\title{
Ethics in Undergraduate Medical Courses in Nepal
}

\author{
Adhikari RK \\ Department of Paediatrics, Kathmandu Medical College \\ Coordinator, Ethical Review Board, Nepal Health Research Council
}

A quick perusal of the Nepal Medical Council (NMC) Rules shows that the physicians registered with the NMC are supposed to follow a number of ethical principles while treating patients or in dealing with their professional colleagues. ${ }^{1}$ There is a list of "do's and don'ts" in the rules book. These rules reflect the tradition in medicine which requires that the physicians treat their patients with respect and dignity, do not harm them; physicians should strive to benefit the patients as far as possible through their treatment and are to make all efforts to be just in their dealing with patients and society in general. The physicians are expected to tell the truth regarding the disease $\mathrm{s} /$ he suspect in a person, and offer information on available options for management of the condition and take consent before starting the treatment. The physicians are required to respect the trust of the patient and it is the utmost duty of the physicians to maintain the confidentiality of the patients and not to divulge information to a person not approved by the patient concerned.

The physicians need appropriate knowledge, skills as well as attitudes to practice according to the rules laid down by the professional council. They will also require necessary skills to communicate with the patients and their caretakers. When there is a wide gap between the physicians, patients and their caretakers; physicians may find it rather difficult to treat them as their equals and treat them with respect. Physicians may find it difficult to communicate effectively and with empathy with the patients who are from different linguistic, cultural, ethnic and socioeconomic backgrounds. Do the present curriculums, followed in the medical colleges in Nepal, prepare the future doctors adequately to practice according to the rules laid down by Nepal Medical Council?

In addition, the rules advise doctors to follow a code of conduct in their dealing with fellow physicians and professional colleagues. Similarly there are explicit rules to be followed while establishing private practice etc.

Furthermore, there are a number of relevant laws which physicians need to be aware of. ${ }^{2}$ All physicians need not be conversant with all the laws but some of these laws have direct implications for those who are engaged in the field of organ transplantation, abortion and counselling of infant and young child feeding etc.

Are there any other attributes that the physicians should strive to achieve? A number of studies conducted to find out the general perception about what qualities are expected in a physician show that the society expects a physician to be compassionate, caring and competent with good communication skills and empathy. ${ }^{3}$

Thus, a physician has to be familiar with the legal provisions that $s /$ he must fulfil in order to be allowed to practice (guided by NMC rules and regulations as well as the code of conduct), must be aware of the rights of the patients and what $\mathrm{s} /$ he is expected to do in order to upheld them as well as be a virtuous person who keeps interests of the patients above self interest. The recent provision of Nepalese constitution has made health a fundamental right and it means that the physicians and health care institutions contribute to make this a reality. Are we providing enough educational experiences to prepare a physician who can fulfil these requirements?

Research is emerging as an important dimension of medical education all over the world including in Nepal. Nepal Health Research Council (NHRC) has been established by an act of parliament in 1991 and one of its main roles is to ensure ethical research in health. NHRC Ethical Guidelines guides the researchers and organizations on how to conduct ethical research. ${ }^{4}$ The guidelines require that the researchers respect the autonomy of the research participant, try to benefit or at least not harm them in the process of research activities and carry out research in a just manner. There are a number of situations in which researchers may be tempted to overlook these principles in their enthusiasm and eagerness to conduct research. It is likely to be more and more difficult if one is not educated in the ethics of health research. It is the responsibility of the medical curriculum and the colleges to help medical students to become educated on this subject.

Medical students are provided with the privilege of learning through history taking and physical examination 
of patients; in the process they acquire confidential information about the patients. The physicians are bound by the code of conduct to maintain the confidentiality and not to gossip around about the patients' condition. But students are not bound by any code. How does the hospital system protect the patient's interest and guide the students to practice correct behaviour? How does it ensure that the students don't take the confidential and privileged information they gather from the patients as a material for talking around?

Medical students come in contact with pharmaceutical industries from the very beginning of their entering the medical college. Early contact with the students is most likely to lead to undue influence on the young minds who may have limited capacity to discriminate between advertisements and unbiased information. How does the medical college monitor the contact between pharmaceutical industries with the students?

Thus, there are a large number of issues which demand education in medical ethics but are the contemporary medical education system prepared to address them? Apparently, current medical curricula put a lot of a stress on acquisition of knowledge and skills and there is very little time for the issues raised here.

A realization among the medical educationists and international agencies that the current educational experiences are not adequate to help medical students to develop skills in dealing with ethical issues has resulted in recommendations to improve education on professionalism and medical ethics in the curricula for training of basic medical graduates.5,6 South East Asia Regional Office of WHO, following a review of the curricula of medical schools in the region had concluded that the teaching of ethics in these countries is in a state of infancy, mostly based in the department of forensic medicine. ${ }^{7}$ This was reconfirmed through a number of in depth studies on ethical dilemmas faced by the physicians in six countries of the region. ${ }^{8}$

As a result of all these initiatives, an expert committee explored the experiences of teaching of ethics in the region and proposed a model curriculum. ${ }^{9}$ The curriculum was reviewed in a meeting of network of medical councils of the region and it was approved with a recommendation that all medical colleges incorporate teaching of medical ethics. The meeting also recommended that teaching materials and a guidebook for the facilitation of teaching of ethics be developed by WHO. ${ }^{10}$ Subsequently, the materials have been developed, reviewed, revised and finally approved by medical councils of the region. Nepal Medical Council has approved of the model curriculum and the learning resources and advised all the universities to follow them. Thus, necessary preparation in terms of curriculum and materials development has been completed.

However, it is relatively easy to agree on a course on medical ethics but quite a different thing to implement it successfully. Implementation of the curricular section on medical ethics would require a faculty trained in the subject, appropriate time slot to teach the course, develop learning materials relevant to the local context and and problems which are to be used with the students; and finally a scheme to evaluate whether the students did learn what they were expected to learn.

According to WHO "Facilitators" Guide for teaching medical ethics to undergraduate students in medical colleges in South East Asia Region", the curricular content consists of core and specific topics. ${ }^{11}$ The teaching learning sessions would consume 15 hours of theory classes and six hours for discussion in the hospital wards or communities. It has been suggested that the department of forensic medicine or medical education should take the lead in organizing the teaching learning sessions; however, the teaching learning activities should be implemented and supervised by a multidisciplinary team consisting of representatives from almost every department.

Tribhuvan University has included the provisions of model curriculum approved by the medical council in its revised 2009 version of the MBBS curriculum. ${ }^{12} \mathrm{~A}$ unit has been established at the National Centre for Health Professions Education at the Institute of Medicine to take necessary steps to implement the curriculum on medical ethics in Maharajgunj Medical Campus and other medical colleges affiliated with Tribhuvan University. The unit has representation from the department of pharmacology, community medicine, medical education and is led by the head of the department of forensic medicine. A faculty development programme was organized in 2012 to orient and train the faculty members to teach the subject. ${ }^{13}$ As a result of this initiative, students joining the MBBS programme at Maharajgunj Medical Campus and Kist Medical College, two colleges under Tribhuvan University have already started to orient first year medical students in medical ethics right from the beginning of the course. ${ }^{14}$ However, the progress has been rather slow and much more needs to be done to prepare the faculty through orientation and training to successfully implement the teaching of ethics in most of the medical colleges.

Medical ethics is mentioned as one of the objectives of MBBS programme in the curriculum of the Kathmandu University (KU) demonstrating KU's commitment towards the need to teach this subject in its constituent and affiliated colleges. ${ }^{15}$ However, it is not very clear how this subject, which does not belong to a specific department, is going to be dealt with. KU can examine the recommendations of the WHO Expert Committee as articulated in the Facilitators' Guide and create the necessary resources for this purpose. A logical follow up to such an action would be to conduct orientation and training programme for the teachers in these colleges and identify the time and resources for providing adequate and appropriate learning experiences to the students so that they are prepared well to practice ethical medicine. 


\section{REFERENCES}

1. Government of Nepal: Nepal Medical Council (Third Amendment) Rules and Regulations; 2057.

2. Swasthya sambandhi ain, Niyamharuko sankalan. $6^{\text {th }}$ edition. Kathmandu: Makalu Publication House; Shrawan 2068.

3. Adhikari RK. Physicians and principle centred delivery of health services. JNMA 2003 Jan-Feb; 42(145).

4. Path R. NHRC: National Ethical Guidelines. NHRC: Kathmandu; 2011.

5. WFME: Basic Medical Education. WFME Global Standards for Quality Improvement. WFME Office, Copenhagen, Denmark: 2003.pg. 10.

6. IIME: Global Essential Requirements in Medical Education.[1 May 2013]. http:/www.iime.org/documents/gmer.htm.

7. Kasturiarachi $N$, Lee $R$, Seaberg J eds. Health Ethics in six SEAR countries: Health Ethics in SEA. WHO, SEARO, New Delhi: 1999; (1).

8. Lie, R. Ethical dilemmas and resource allocation: Two questionnaire study, Health Ethics in South East Asia. WHO, SEARO, New Delhi: 1 999;(2).
9. WHO: Module for teaching medical ethics to undergraduates. WHO, SEARO: 2009.

10. WHO: Report of the expert group meeting to finalize the handbook and facilitators guide. Dhaka, Bangladesh: 2009 27-30 October; WHO, 2010.

11. WHO: Facilitators' Guide for teaching medical ethics to undergraduate students in medical colleges in the South East Asia region. WHO, SEARO; 2010.

12. Medical Education Department, TU, IoM: Curriculum for Bachelor of Medicine and Bachelor of Surgery. Maharajgunj, Kathmandu; 2008.

13. Schedule of the training programme, orientation of first year students: NCHPE, IOM, 2012 ( personal communication).

14. Kist Medical College. TU: Schedule of orientation of first year students; 2012 (Personal communication)

15. Kathmandu University/Dhulikhel Hospital: Curriculum: Bachelor of Medicine and Bachelor of Surgery. Revised edition. KU School of Medical Sciences/Dhulikhel Hospital, Dhulikhel;2011. 